\title{
Atitudes linguísticas na fala dos costarriquenses
}

\author{
Linguistic attitudes in the costarrians speech
}

\author{
Wanessa Rodovalho Melo Oliveira \\ Universidade Estadual de Mato Grosso do Sul
}

- RESUMO: Este artigo trata das atitudes linguísticas presentes na fala dos nativos da cidade de Costa Rica - MS, tendo como objetivos conhecer um pouco sobre a fala dos costarriquenses e, apontar como estes veem a sua língua e das demais pessoas. Este estudo visa identificar qual fala de prestígio é mais relevante para esses sujeitos, considerando suas atitudes linguísticas pautadas nos estudos da Sociolinguística. Utilizou-se como base metodológica a aplicação de um questionário, cujos dados evidenciaram que boa parte dos informantes não acredita ter sotaque e, que a língua de maior prestígio é a que eles falam.

- PAlavraS-CHAVE: Atitudes Linguísticas, Costa Rica, Falantes Nativos.

- ABSTRACT: This article is about the linguistic attitudes present on speech the native people of the city of Costa Rica- MS, and having as objectives to know a little about the speech of the costarrians and, to show how they see their language and of the others people. This study demand to identify which that privileged speech is the most important to these people, considered their linguistic attitudes based the study of Sociolinguistic. Was utilized how methodological support the application of one the questionary, whose information showed that a large part of the informants don't believe they linguistics accent and, the most prestigious language is the one they speak.

- KEYWORDS: Linguistic Attitudes, Costa Rica, Native Speakers.

\section{Introdução}

A língua portuguesa com o passar do tempo sofreu muitas transformações em seu vernáculo, sendo essas mudanças responsáveis por contribuir com a construção da identidade brasileira. Tal feito tornou-se notável, considerando ouvir o sotaque de uma pessoa e já conseguir identificar a partir da fala, a qual região pertence, exaltando dessa maneira, a cultura e a construção linguística.

Cada região tem suas particularidades que podem sofrer variações, dependendo do grau de estudo, das pessoas que mantêm contado, assim como outros fatores como a idade, o sexo e o contexto social em que está inserida. A existência dessa pluralidade cultural, registrada não apenas no comportamento, mas também na fala, nas atitudes e crenças linguísticas, faz com que os falantes criem alguns estereótipos acerca da sua própria língua e da língua dos outros indivíduos. Contudo, tal prática pode gerar duas consequências: prestígio ou preconceito linguístico.

Ao determinar preferência por uma língua, é provável que desprestigie outra, pois em alguns casos pode soar estranho ou irritante, por ser, por exemplo, um sotaque 
diferente da pessoa, ou ainda, por apresentar paramentos linguísticos adversos à realidade em que está habituada.

As atitudes linguísticas inerentes ao campo da Sociolinguística, foram pautadas a partir dos primeiros trabalhos realizados por psicólogos sociais, com vistas a analisar como se dão as preferências e crenças que envolvem estas atitudes, que na realidade, apenas refletem a identidade do falante transparecendo sua opinião e suas próprias verdades.

Partindo dessa premissa, a opção metodológica dessa pesquisa está alicerçada na aplicação de um questionário, previamente elaborado, que contempla ao todo, cinco questões definidas e direcionadas aos vinte falantes nativos do município de Costa Rica - MS, sendo esses sujeitos compreendidos por dez homens e dez mulheres, com idades entre 20 e 65 anos.

Ressalta-se, que devido à pandemia mundial causada pelo Covid-19, tendo o isolamento social como regra, a coleta dos dados dessa pesquisa foi realizada por meio do aplicativo WhatsApp, por se tratar de uma ferramenta tecnológica que permite o acesso a comunicação de forma mais rápida e eficaz, além é claro, de permitir conhecer as atitudes linguísticas dos participantes desse estudo, como também apontar como esses sujeitos veem a sua língua e das demais pessoas e, ainda, investigar qual língua é tida com maior e menor prestígio social.

A opção pelo uso de em questionário semiestruturado, seguiu as orientações de Manzini (2003) ao entender a necessidade de elaboração de um roteiro de perguntas básicas e principais que atinjam os objetivos pretendidos, considerando que mediante seu uso é possível um planejamento da coleta de informações, a fim de atingir o objetivo da pesquisa. Para isso, será pautada nos estudos sociolinguísticos, tendo os psicólogos Lambert e Lambert (1966) como embasamento teórico acerca das atitudes linguísticas, assim como o método de análise de Labov, de natureza quantitativa segundo Tarallo (1985).

\section{Metodologia}

O corpus apresentado via WhatsApp aos sujeitos dessa pesquisa, foi construído a partir das cinco questões abaixo:

1. Qual língua você fala?

2. Qual língua você acha mais bonita?

( ) paulista ( ) mineira ( ) sulista ( ) goiana ( ) costarriquense ( ) alagoana

3. Qual língua você acha mais feia?

( ) paulista ( ) mineira ( ) sulista alagoana

4. Qual língua é a mais correta?

( ) paulista ( ) mineira ( ) sulista ( ) goiana ( ) costarriquense ( ) alagoana

5. Você tem sotaque?

( ) $\operatorname{sim} \quad$ ( ) não

As questões 2, 3 e 4 possuem as mesmas alternativas (paulista, mineira, sulista, goiana, costarriquense e alagoana), que foram pensadas, com vistas ao grande número de migrantes dessas regiões. 
A escolha dos informantes para a realização e concretização desse estudo, foi feita de forma objetiva e planejada, visando contemplar a faixa etária de 20 a 65 anos de idade, englobando a mesma quantidade de homens e mulheres, formando, assim, um total de 20 participantes, que possuem a escolaridade do ensino básico ao superior. Vale ressaltar, que durante a realização dessa pesquisa, em momento algum, se objetivou ter influências sobre as opiniões dos participantes, apenas foi incentivado que respondessem ao questionário da maneira mais verídica possível, sem a preocupação com a questão do certo ou do "errado".

Segue abaixo, a tabela com a síntese de perfil sobre os informantes:

Quadro 1: Perfil dos informantes

\begin{tabular}{|c|c|c|c|c|c|c|}
\hline & $\begin{array}{l}\text { Sexo Masculino } \\
\text { Profissão }\end{array}$ & $\begin{array}{c}\text { Nível de } \\
\text { Escolaridade }\end{array}$ & Idade & $\begin{array}{l}\text { Sexo Feminino } \\
\text { Profissão }\end{array}$ & $\begin{array}{c}\text { Nível de } \\
\text { Escolaridade }\end{array}$ & Idade \\
\hline Informante 1 & Advogado & Ensino Superior & 23 & Recepcionista & Ensino Básico & 20 \\
\hline Informante 3 & Pedreiro & Ensino Básico & 28 & Manicure & Ensino Básico & 29 \\
\hline Informante 5 & Técnico em RH & Ensino Superior & 38 & Vendedora & Ensino Básico & 36 \\
\hline Informante 6 & Fisioterapeuta & Ensino Superior & 39 & Dentista & Ensino Superior & 40 \\
\hline Informante 7 & Radialista & Ensino Básico & 41 & $\begin{array}{c}\text { Caixa de } \\
\text { Supermercado } \\
\end{array}$ & Ensino Básico & 42 \\
\hline Informante 10 & Professor & Ensino Superior & 64 & Advogada & Ensino Superior & 57 \\
\hline
\end{tabular}

\section{Contexto histórico sobre a cidade de Costa Rica - MS}

Intencionando conhecer o locus da pesquisa, propõe-se alguns breves apontamentos sobre o contexto histórico do município de Costa Rica - MS. Para isso, pesquisas como a de Marlei Cunha (1992; 2009), fazem-se necessárias, pois permitem entender como se formaram os agrupamentos étnicos que geraram os habitantes dos povoados, vilas e cidades desta rica e importante região sul-mato-grossense.

Cunha (1992) arrazoa que a cidade de Costa Rica, localizada no Estado de Mato Grosso do Sul, tem como um dos fundadores, José Ferreira da Costa, nascido em 14 de abril de 1892, de origem das fazendas de Vassourinha e Bálsamo na cidade de Nioaque (região leste deste Estado) e falecido em 11 de maio de 1983, na cidade de Goiânia, e transportado para Costa Rica onde foi velado e sepultado.

Cunha (1992) apresenta a trajetória de José Ferreira da Costa ao evidenciar que sua vinda às terras que hoje formam a cidade de Costa Rica, esteve relacionada ao fato de sua sogra, a viúva Dona Rita Paula de Souza, envergonhada diante dos princípios morais que a época preconizava, por sua filha Zulmira se entregar ao rapaz Basílio Pereira sem oficializar a união, decidir vender e deixar bens de raiz para aventurar-se sertão adentro, ordenando ao seu filho mais velho, Aparício Carvalho de Souza e ao seu genro José Ferreira da Costa que fossem à frente, a fim de encontrarem terras para toda a família viver. Assim, os dois aventureiros souberam de terras boas e férteis próximas ao Rio Sucuriú e, após uma visita, por volta de 1926, levaram toda a família em uma jornada árdua, considerando que percorreram todo o trajeto em carros de bois, além é 
claro, das muitas dificuldades encontradas pelo trajeto, como estradas acidentadas, atravessia de rios, mosquitos sangrentos e surto de febre amarela. Durante todo o percurso, alimentaram-se de arroz e feijão, e carne, quando pelo caminho compravam uma vaca, sendo necessário carneá-la e charqueá-la.

Segundo análises de Cunha (1992), ao chegarem às terras que atualmente pertencem à região de Costa Rica, José Ferreira da Costa em 1943, contraiu seu segundo casamento com Dona Maria Tosta Barbosa, que possuía de herança de seu falecido marido duas grandes fazendas, fazendo dessas terras um bom negócio ao abrir um grande loteamento e vender lotes aos interessados, mas, também fez doações às mulheres que não tinham maridos e aos pobres. Sonhava assim, em ver uma cidade surgir e, este sonho se realizou, pois em 1961 compareceu ao cartório de Camapuã (região norte deste mesmo Estado) para legalizar e cuidar dos aspectos jurídicos do patrimônio já existente. Surgiu dessa maneira, a vila denominada "Costa Rica", que recebeu esse nome devido ao fato de "Costa" se tratar do sobrenome do fundador, e "Rica" pelas paisagens e encantos que apresenta em toda sua extensão.

Tal loteamento, segundo Cunha (2009, p. 190) contava com "159 lotes de terrenos com várias dimensões. Os referidos lotes acham-se divididos em quadras com ruas traçadas, locais apropriados para praças, reservas para edifícios públicos, campos de aviação, constituindo tudo um verdadeiro patrimônio". A aceitação da região foi tão grande que logo as primeiras casas e os primeiros comerciantes chegaram, "o povoado se tornou Distrito de Camapuã em 21 de janeiro de 1964 (Lei 2.132) e elevado à categoria de município (Lei 76, de 12 de maio de 1980), com desmembramento de porções dos municípios de Camapuã e Cassilândia." (MUNICÍPIO DE COSTA RICA, 2013).

Diante do interesse em "formar um novo município com a área que pertencia aos distritos de Costa Rica" (CUNHA, 1992, p. 185), propuseram a emancipação desta região da cidade de Camapuã, já que contava com mais de 200 residências, com população estimada em 11.000 habitantes e o eleitorado não sendo inferior a 2.500 . Assim, Costa Rica foi emancipada em:

\footnotetext{
11 de maio de 1980, o governador Marcelo Miranda Soares assina a Lei número 76 e cria o Município de Costa Rica - MS. O ato foi publicado no Diário Oficial no dia 12 de maio de 1980. Costa Rica passa a ter independência político-administrativa e autonomia para desenvolver-se. (ASSECOM/PMCR, 2019).
}

Atualmente a cidade é conhecida como a "Capital do Algodão" e dos "Esportes de Aventuras", tendo em vista que seu potencial turístico tem aumentado, sendo berço para muitos eventos nacionais e internacionais relacionados aos esportes. Segundo informações apresentadas pelo Atlas Geográfico da cidade de Costa Rica (2007, p. 14), esta cidade "está localizada a aproximadamente $338 \mathrm{~km}$ de distância da capital do Estado, Campo Grande" e "limita-se a noroeste com Alcinópolis, a norte e nordeste com o município de Mineiros (GO), a leste com Chapadão do Sul”, e possui uma população estimada em 19.695 pessoas, segundo o Censo (IBGE) de 2010.

Costa Rica está localizada ao nordeste, por isso participa da Tríplice Fronteira, pois seu território faz divisa com os estados de Mato Grosso e Goiás, conforme figura abaixo:

Figura 1: Localização do município de Costa Rica - MS 


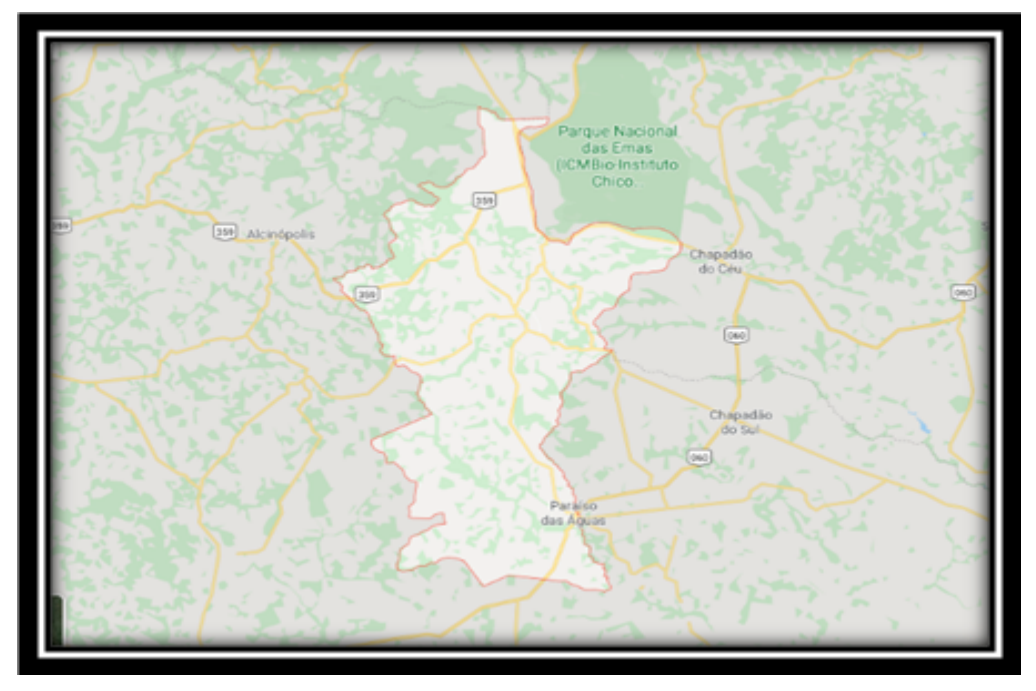

Fonte: Print screen Google Maps Place Costa Rica

Trata-se de uma região promissora por conter muitas paisagens a serem exploradas, além do fato da lavoura de algodão, soja, cana de açúcar, milho, e, na entressafra o cultivo de girassol, aquecerem a economia local. A Atvos, usina de bioenergia, é responsável por gerar muitos empregos, sendo esse um dos principais motivos pelo crescente número de migrantes, principalmente os alagoanos que encontraram na referida cidade, um porto financeiro capaz de ajudar a essas famílias tão necessitadas.

No que tange a colonização, os sulistas chegaram à região fundando cidades e implantando lavouras que ajudaram no progresso e desenvolvimento do município, com isso, influenciaram nas atitudes linguísticas desse povo, além de emprestar o vocabulário aos nativos, como o uso da palavra "guri" relativo à "criança". Outros aspectos também sofreram influências, como o caso da culinária, tendo o churrasco, a cuca e o chimarrão como hábitos culinários presentes no cotidiano dos costarriquenses.

O centro-oeste também recebeu influências mineiras, por isso, muitos costarriquenses acreditam falar a língua portuguesa caipira, conforme observado no vocabulário, principalmente das pessoas com mais idade ao falarem trem, troço, uai, e por possuírem a pronúncia do " $\mathrm{r}$ " retroflexo, conhecido como um " $\mathrm{r}$ " mais puxado. Além das atitudes linguísticas, a culinária também sofreu forte influência da colonização, como o caso da pamonha, do arroz com pequi e do frango com quiabo.

O multiculturalismo, isto é, a mistura de culturas é o que torna uma localidade cheia de encantos, pois são essas ações que constroem as crenças e as atitudes linguísticas inerentes ao processo de formação da identidade de cada indivíduo, considerando o grupo social em que pertence. Assim sendo, de certa maneira, quem ajudou a construir a cidade de Costa Rica, também deixou um marco registrado na história e identidade desse povo.

\section{Pressupostos teóricos: As atitudes linguísticas}

Os estudos sobre as atitudes linguísticas ganharam mais evidências quando os psicólogos sociais Lambert e Lambert (1966) investigaram as atitudes linguísticas de jovens universitários canadenses falantes bilíngues de inglês e francês. Como resultado no "Canadá, o inglês e seus falantes gozavam de um prestígio e pesava sobre o francês e 
seus falantes um estigma." (JACUMASSO, 2018, p. 44). Para Calvet "essa técnica, desenvolvida no campo da psicologia social, foi depois utilizada por linguistas, permitindo destacar atitudes ou representações linguísticas". (CALVET, 2002, p. 66).

As atitudes linguísticas estão relacionadas à construção da identidade do falante, portanto, é o que ele acredita e toma para si como verdade, consequentemente, as suas reações frente às outras pessoas, demonstram na realidade, não somente o que acredita, mas suas concepções e paradigmas. No campo da Psicologia é definida como:

\begin{abstract}
Uma atitude é uma maneira organizada e coerente de pensar, sentir e reagir em relação a pessoas, grupos, questões sociais ou, mais genericamente, a qualquer acontecimento ocorrido em nosso meio circundante. Seus componentes essenciais são os pensamentos e as crenças, os sentimentos (ou emoções) e as tendências para reagir. Dizemos que uma atitude está formada quando esses componentes se encontram de tal modo interrelacionados que os sentimentos e tendências reativas específicas ficam coerentemente associados com uma maneira particular de pensar em certas pessoas ou acontecimentos. (LAMBERT, 1966, p. 77-78)
\end{abstract}

Conforme observado nessa descrição, as atitudes estão relacionadas à bagagem intelectual e sentimental do falante, logo, a construção dessas atitudes e das crenças está vinculada aos lugares em que a pessoa frequentou, às interferências familiares, ao convívio social, seja na escola, no trabalho ou no ciclo de amizade, nas culturas que conheceu, sendo esses os elementos que formam o caráter de identidade de uma pessoa.

Labov, principal representante da Sociolinguística, comenta sobre o trabalho de Lambert:

\footnotetext{
o princípio essencial que emerge do trabalho de Lambert é o de que existe um conjunto uniforme de atitudes frente à linguagem que são compartilhadas por quase todos os membros da comunidade de fala, seja no uso de uma forma estigmatizada ou prestigiada da língua em questão. (LABOV, 2008, p. 176)
}

Existe uma ideologia de significados que acompanha o falante e torna evidente, de certa maneira prestigiada, a língua com um papel social importante. Em cosonância, acrescenta que as variações podem estar relacionadas às classes sociais, ao espaço físico que o falante ocupa, ao grupo profissional que pertence, ao seu sexo, à modalidade de linguagem que utiliza para se comunicar e à situação de interação a que está exposto, e, que estas variações podem ser observadas em uma mesma comunidade. (LOPES, 2000).

Partindo desse entendimento, o falante pode considerar que a sua própria fala é de prestígio, pois "em todas as comunidades existem variedades que são consideradas superiores e outras inferiores" (ALKMIN, 2006, p. 39), que, consequentemente, podem gerar o preconceito linguístico ao menosprezar a fala do outro, considerando-a feia ou inferior a sua, mas existe também o preconceito relacionado àquelas pessoas que procuram, gramaticalmente, falar de maneira correta, extrapolando às vezes, o nível de prestígio empregado em sua fala, tendo em vista o lugar em que está.

Assim, é inadmissível que uma pessoa seja martirizada por suas escolhas linguísticas, crenças, modo de falar ou até mesmo seu sotaque, considerando que toda maneira de discriminação deve ser combatida. Bagno cita que "o tipo mais trágico de preconceito não é aquele exercido por uma pessoa em relação a outra, mas o preconceito que uma pessoa exerce sobre si mesma" (BAGNO, 1999, p. 97). Portanto, a 
língua se revela à medida que os pensamentos são formados ao longo do tempo, construindo a visão da sua própria identidade.

Em contra ponto, Tarallo afirma que "atitudes linguísticas são as armas usadas pelos residentes para demarcar seu espaço, sua identidade cultural, seu perfil de comunidade, de grupo social separado" (TARALLO, 1985, p.14). Tal apontamento pode ser confirmado nesta pesquisa, pois a maioria dos costarriquenses revelou o desprestígio em relação à fala dos alagoanos, considerando-a feia, provavelmente este fator está imbricado ao aspecto social desta região.

Diante dessa observação, nessa próxima seção, serão expostos os resultados dessa pesquisa.

\section{Análise dos dados}

A primeira pergunta busca conhecer a visão do falante sobre a língua que fala, tendo em vista que tal entendimento pode acarretar prestígio social, ou não, acerca da sua maneira de falar.

\section{Gráfico 1 - Qual língua você fala?}

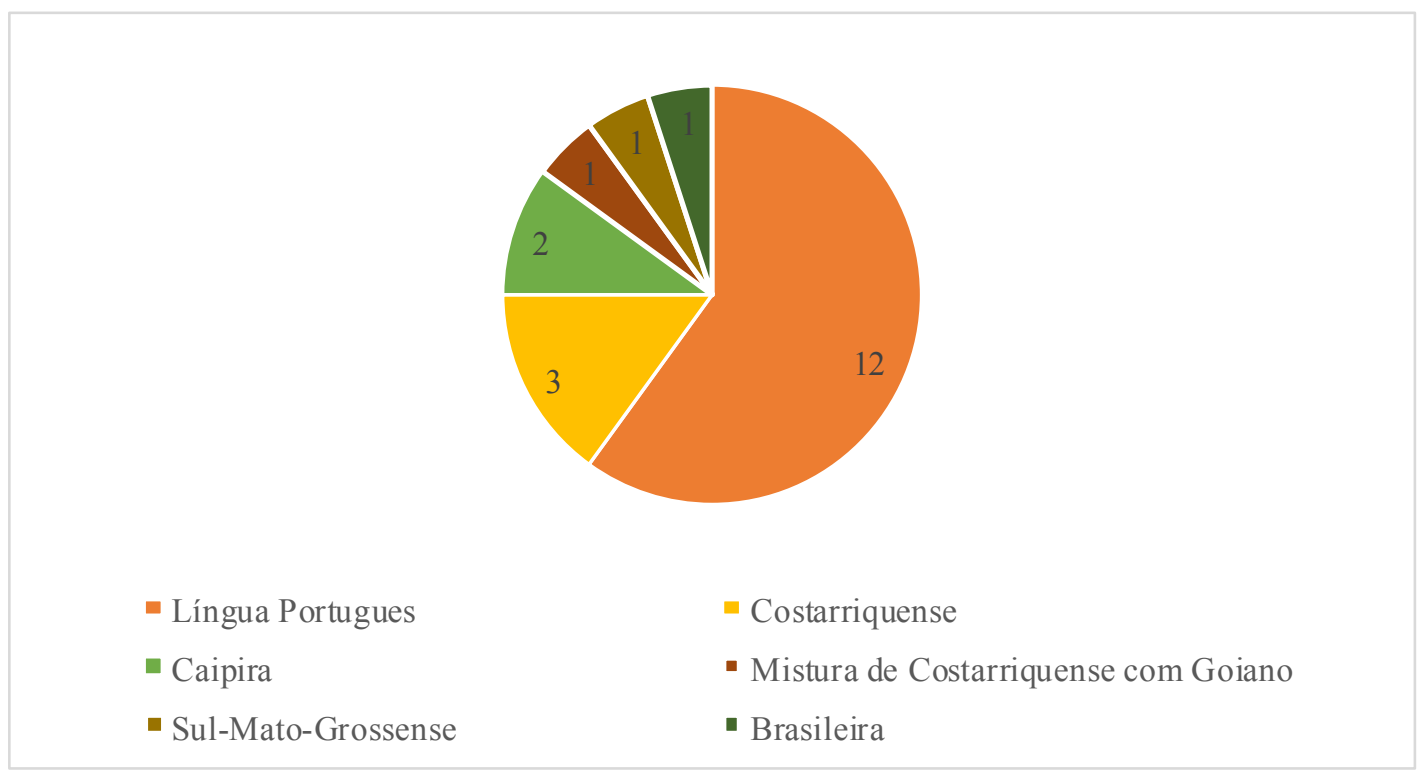

Fonte: A autora (2020)

A resposta que predominou foi a Língua Portuguesa ou Português, conforme já era previsto, tendo em vista ser a língua falada no Brasil, no entanto, o que merece destaque é a quantidade de variantes registradas, já que três pessoas designaram falar a língua Costarriquense. Contudo, mais surpreendente foi o registro de duas pessoas, totalmente acarretas de identidade da região, designarem a sua fala como Caipira. Uma pessoa classificou a sua fala como Sul-Mato-Grossense, outra como Brasileira, e uma assumiu o sotaque da Mistura de Costarriquense com Goiano.

As marcas de identidade não estão inscritas no real, embora os elementos sobre os quais as representações de identidade são construídas sejam dele selecionadas. Estão em pauta, portanto, os processos de apreensão do mundo 
social: esta apreensão dá-se, sempre, através de atos de pensamento e linguagem, cujas coordenadas são geradas social e culturalmente. (PENNA, 1992, p. 167).

O fato de alguns participantes optarem por ter como fala a língua Costarriquense, evidencia que as atitudes linguísticas do falante nativo estão enraizadas nas suas crenças, na concepção identitária e na valorização da cultura local.

\section{Gráfico 2 - Qual língua você acha mais bonita?}

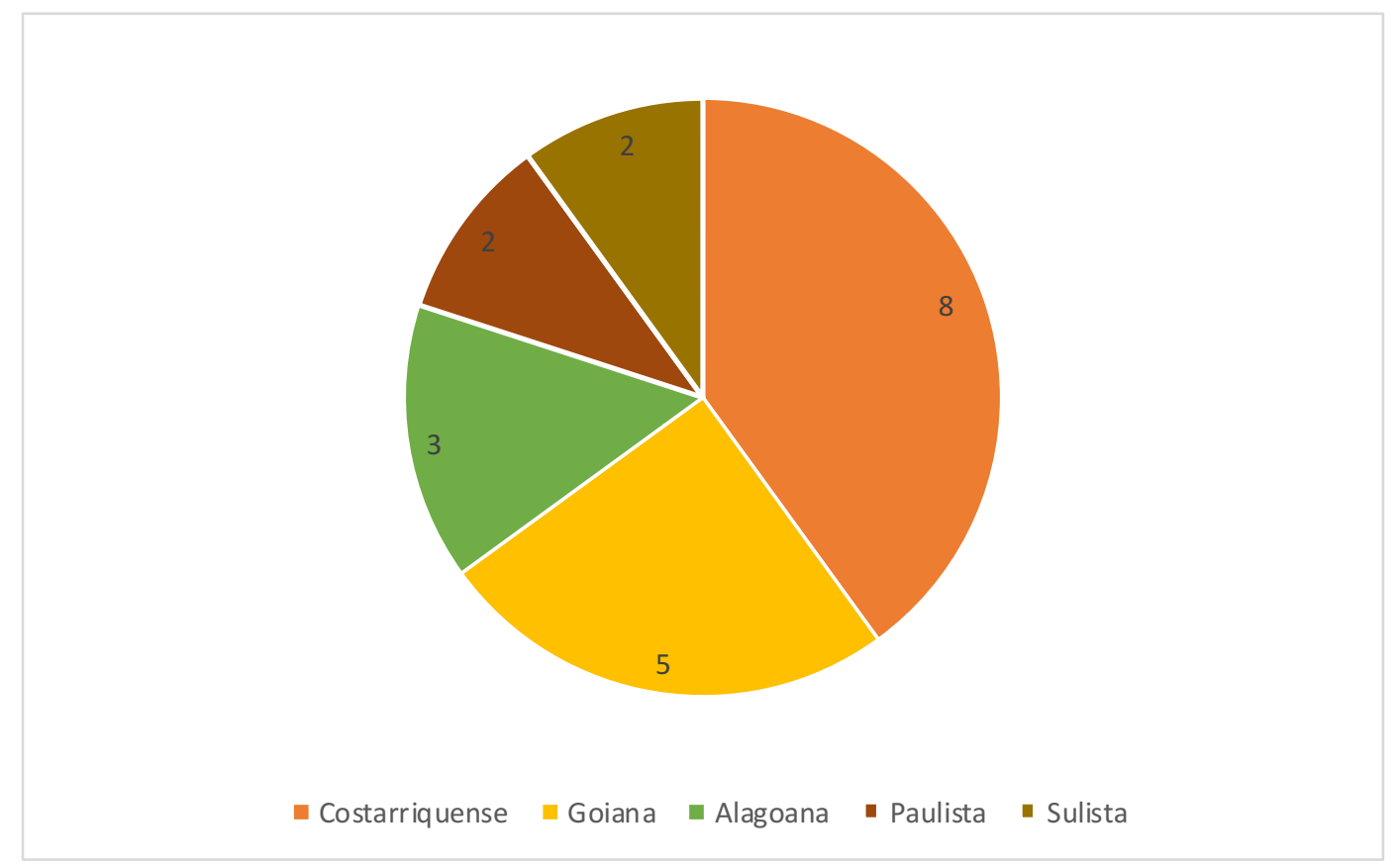

Fonte: A autora (2020)

A língua Costarriquense foi considerada pelos informantes como a de maior prestígio quanto a sua beleza. A atitude linguística evidenciada é positiva, pois mostra que a maioria não sente a necessidade de esconder o seu sotaque ou de tentar modificálo. Muitos que escolheram esta opção são do sexo masculino e não possuem ensino superior. 


\section{Gráfico 3 - Qual língua você acha mais feia?}

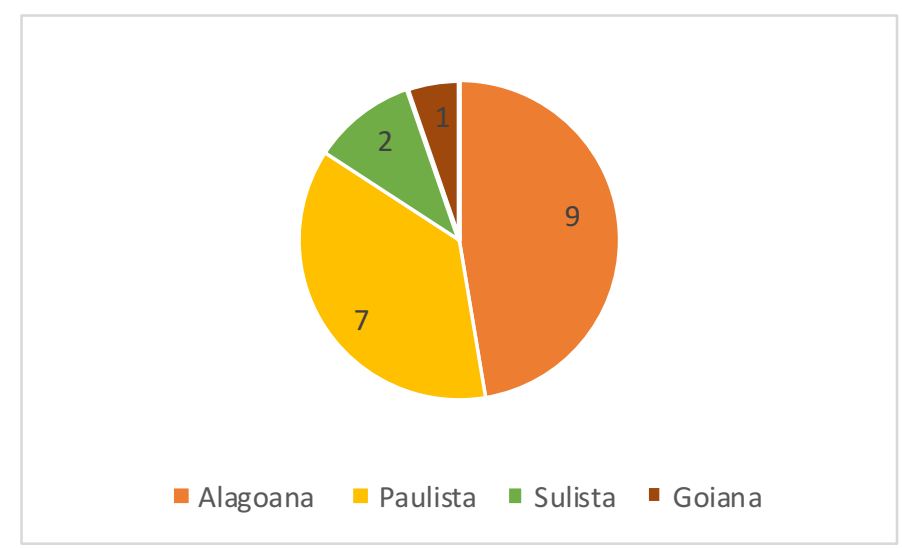

Fonte: A autora (2020)

O registro da escolha da língua Alagoana como a de menos prestígio, revela-se, talvez, pelo fato da cidade de Costa Rica receber, recentemente, vários migrantes advindos dessa região, considerando que muitos trabalham na usina Atvos, causando assim, certa estranheza aos falantes nativos no que concerne aos seus costumes e fala.

Segundo estudos de Calvet "as pessoas serão julgadas segundo seu modo de falar." (CALVET, 2002, p. 69), tal fato gera a depreciação às atitudes linguísticas do falante, pois quando se julga alguém, consequentemente, julga a si mesmo, uma vez que não existe um sotaque mais bonito que o do outro, haja vista que "existe todo um conjunto de atitudes, de sentimentos dos falantes para com suas línguas, para com as variedades de línguas e para com aqueles que as utilizam, que torna superficial a análise da língua como simples instrumento." (CALVET, 2002, p. 65).

\section{Gráfico 4 - Qual língua é a mais correta?}

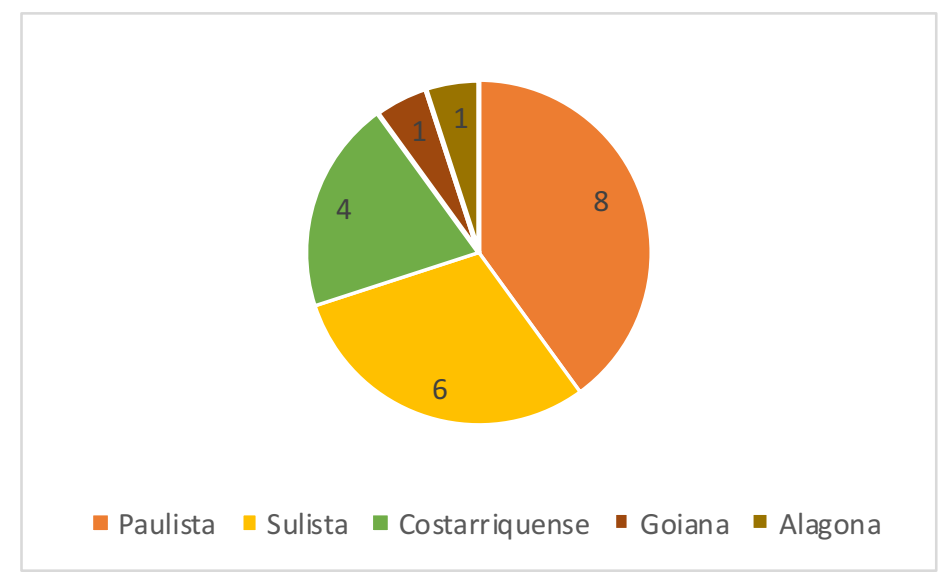

Fonte: A autora (2020)

Segundo os informantes dessa pesquisa, a língua Paulista, seguida pela Sulista, são consideradas como as mais corretas. Em relação a menos prestigiosa, tem-se a Mineira, já que não foi registrada por nenhum participante.

Sobre esse ponto Calvet registra que: 
Existe na sociedade o que poderíamos chamar de olhares sobre a língua, de imagens da língua, em uma palavra, normas que podem ser partilhadas por todos ou diferenciadas segundo certas variáveis sociais (o sexo, no exemplo de Norwich) e que geram sentimentos, atitudes, comportamentos diferenciados. (CALVET, 2002, p. 72).

A língua Costarriquense ficou em terceiro lugar, indicando que os participantes não consideram falar corretamente, a citação de Bortoni-Ricardo pode justificar este acontecimento: "as variantes não padrão presentes na língua não são erros, mas, sim, diferenças, mais produtivas na modalidade oral da língua e em estilos não monitorados." (BORTONI-RICARDO, 2014, p. 158).

Por esse prisma, pode-se entrever o fato de muitos falantes nativos da cidade de Costa Rica, serem pessoas com baixa escolaridade, já aqueles que possuem nível superior completo, não falam conforme preconiza a norma padrão de prestígio, contudo, tal prática não remete ao erro. Alguns apontamentos podem ser feitos, como o caso das palavras que têm o fonema $l h$ na escrita, como vocalização do -lh- por i, como exemplos têm-se as palavras fia, muié, entre outras. Mais uma marca refere-se quando se faz menção a cidade de Costa Rica, pois muitos usam preposições erradas, como por exemplo: "vamos na Costa Rica" e "voltamos da Costa Rica".

\section{Gráfico 5 - Você tem sotaque?}

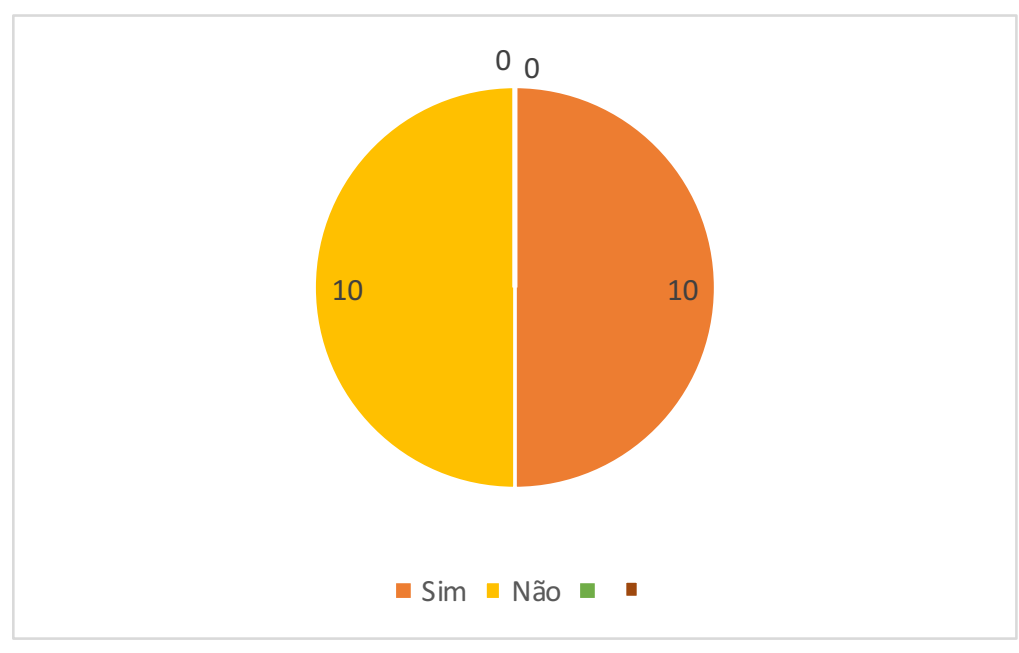

Fonte: A autora (2020)

Este gráfico demonstra um dado inesperado, considerando que todas as pessoas possuem sotaque, a não ser aquelas que passam por treinamento fonoaudiólogo para reduzir seu sotaque. Sobre isso:

A verdade é que no Brasil, embora a língua falada pela grande maioria da população seja o português, esse português apresenta um alto grau de diversidade e de variabilidade, não só por causa da grande extensão territorial do país - que gera as diferenças regionais, bastante conhecidas e também vítimas, algumas delas, de muito preconceito. (BAGNO, 1999, p. 16).

É esta diversidade responsável pelas atitudes linguísticas presentes na fala dos costarriquenses, considerando observar o " $\mathrm{r}$ " mais puxado, muitas vezes comparado ao " $r$ " mineiro, sendo essa uma identidade linguística registrada na região, pois os falantes 
vão envolvendo-se com os migrantes, misturando as línguas e as culturas, formando, assim, novas construções linguísticas.

Conclui-se este trabalho com as considerações de Bagno sobre a língua portuguesa:

\begin{abstract}
$\mathrm{Na}$ verdade, como costumo dizer, o que habitualmente chamamos de português é um grande "balaio de gatos", onde há gatos dos mais diversos tipos: machos, fêmeas, brancos, pretos, malhados, grandes, pequenos, adultos, idosos, recém-nascidos, gordos, magros, bem-nutridos, famintos etc. Cada um desses "gatos" é uma variedade do português brasileiro, com sua gramática específica, coerente, lógica e funcional. (BAGNO, 1999, p. 18).
\end{abstract}

\title{
Conclusão
}

Considerando os dados apresentados acerca da pesquisa que versa discutir sobre "Atitudes linguísticas na fala dos costarriquenses", constatou-se que a língua costarriquense é estimada pelos falantes nativos participantes dessa pesquisa, como prestigiosa por ser considerada a mais bonita, porém, evidenciou-se que consideram como correta, a língua paulista, sulista e, em terceira posição, a costarriquense.

Importante ainda registrar que a língua mineira não foi escolhida como alternativa em nenhuma das questões, revelando que os informantes possuem certo desprestígio à língua, mesmo tendo muitos elementos dessa região enraizados na construção linguística local.

As atitudes linguísticas nas respostas apresentadas apontam para um favorecimento da língua da própria cidade e, que de certo modo, as diversidades apenas contribuíram para a construção da cultura e da identidade dos falantes.

\section{REFERÊNCIAS}

ALKMIM, Tânia Maria. Sociolinguística: parte I. In: MUSSALIM, Fernanda; BENTES, Anna Christina (orgs.). Introdução à linguística: domínios e fronteiras. 6 a .ed. São Paulo: Cortez editora, 2006.

ASSECOM/PMCR. Costa Rica comemora dia 12 de maio 39 anos de emancipação político-administrativa. Município de Costa Rica, 2019. Disponível em: $<$ https://www.costarica.ms.gov.br/noticia/2631-costa-rica-comemora-dia-12-de-maio39-anos-de-emancipacao-politico-administrativa.html $>$ Acesso em: 19 de junho de 2020.

Atlas Geográfico Costa Rica: localização, geologia, clima, hidrografia, vegetação, infra-estrutura urbana/Prefeitura Municipal de Costa Rica - Campo Grande: RE9 Idéias, 2007. 65 p.: il.: $30 \mathrm{~cm}$.

BAGNO, Marcos. Preconceito Linguístico: o que é, como se faz. São Paulo: Edições Paulinas, 1999.

BORTONI-RICARDO, Stella Maris. Manual de Sociolinguística. São Paulo: Contexto, 2014.

CALVET, Louis-Jean. Sociolinguística: uma introdução crítica. Tradução Marcos Marcionilo. São Paulo: Parábola, 2002. 
CUNHA, Marlei. Costa Rica: história e genealogia. $1^{\text {a }}$ ed. Campo Grande - MS: Editora Fenix, 1992.

CUNHA, Marlei. Costa Rica: Pioneiros que construíram o Progresso de Costa Rica. Editora Caiapó, 2009.

Diário Oficial Eletrônico de Mato Grosso do Sul. Disponível em: www.imprensaoficial.ms.gov.br/pdf/DO337_13_05_1980.pdf. Acesso em: 22 de junho de 2020.

JACUMASSO, Tadinei Daniel. Atitudes, representações e políticas linguísticas: lugares que a língua espanhola ocupa no imaginário de paranaenses / Tadinei Daniel Jacumasso; orientador Adrián Pablo Fanjul. - São Paulo, 2018.

LABOV, William. Padrões sociolinguísticos. São Paulo: Parábola Editorial, 2008.

LAMBERT, William W.; LAMBERT, Wallace E. Psicologia Social. Rio de Janeiro: Zahar editors, 1966.

LOPES, Iveuta de Abreu. "Variação linguística e ensino de língua portuguesa: alguns pressupostos básicos". In: COSTA, Catarina de Sena S. M. (Org.). Linguística e ensino de Língua Portuguesa: sensibilidade cultural e interação didático-pedagógica. Teresina: EDUFPI, 2000.

MANZINI, E. J. Considerações sobre a elaboração de roteiro para entrevista semiestruturada. In: MARQUEZINE: M. C.; ALMEIDA, M. A.; OMOTE; S. (Orgs.) Colóquios sobre pesquisa em Educação Especial. Londrina:eduel, 2003. p.11-25.

MUNICÍPIO DE COSTA RICA, 2013. Disponível em: $<$ https://www.costarica.ms.gov.br/nossacidade/4-costa-rica.html $>$ Acesso em: 19 de junho de 2020.

PENNA, Maura. O que faz ser nordestino: identidades sociais, interesses e o "escândalo" Erundina. São Paulo: Cortez, 1992.

TARALlO, Fernando. A pesquisa sociolinguística. São Paulo: Ática, 1985.

Print screen Google Maps Place Costa Rica, 2020. Disponível em $<$ https://www.google.com/maps/place/Costa+Rica+-+MS,+79550-000/@,-18.6118515,53.7301669,9z/data $=! 3 \mathrm{~m} 1$ !4b1!4m5!3m4!1s0x94829965145a302b:0x3e42f471272d284 b! $8 \mathrm{~m} 2 ! 3 \mathrm{~d}-18.5305058 ! 4 \mathrm{~d}-53.1437427>$. Acesso em 18 de junho de 2020.

Recebido em: junho de 2020. Aprovado em: agosto de 2020.

Como citar este trabalho:

OLIVEIRA, W. R. M. Atitudes linguísticas na fala dos costarriquenses. Traços de Linguagem, v. 4, n. 1, p. 38-49, 2020. 